Вісник Дніпропетровського університету. Біологія. Екологія. - 2012. - Вип. 20, т. 1. - С. 107-111.

Visnyk of Dnipropetrovsk University. Biology. Ecology. - 2012. - Vol. 20, N 1. - P. 107-111.

УДК 597.08-19(285.2:597)

\author{
И. А. Столбунов
}

Институт биологии внутренних вод им. И. Д. Папанина РАН

\title{
ИХТИОФАУНА ВОДОХРАНИЛИЩ ЦЕНТРАЛЬНОГО ВЬЕТНАМА
}

Впервые изучен видовой состав, распределение и численность рыб в пелагиали и литорали четырех водохранилищ Центрального Вьетнама (Суои Чау, Кам Лам, Да Бан, Суои Зау). По данным исследований, ихтиофауна водоемов представлена 43 видами из 19 семейств рыб.

\section{І. А. Столбунов}

Інститут біології внутрішніх вод ім. І. Д. Папаніна РАН

\section{ІХТІОФАУНА ВОДОСХОВИЩ ЦЕНТРАЛЬНОГО В'ЄТНАМУ}

Уперше досліджено видовий склад, розподіл і чисельність риб у пелагіалі та літоралі чотирьох водосховищ Центрального В'єтнаму (Суоі Чау, Кам Лам, Да Бан, Суоі Зау). За даними досліджень, іхтіофауна водойм представлена 43 видами з 19 родин риб.

\section{A. Stolbunov}

Institute of Biology of Inland Waters, Russian Academy of Sciences

\section{ICHTHYOFAUNA OF THE RESERVOIRS OF CENTRAL VIETNAM}

Species composition, distribution and abundance of fish in the pelagic and littoral zone of four reservoirs of Central Vietnam (Suoi Chau, Kam Lam, Da Ban and Suoi Dau) were studied first. According to the research data the fish community of the reservoirs is represented by 43 species of 19 fish families.

\section{Введение}

Впервые исследованы видовой состав, встречаемость и численность рыб водохранилищ Суои Чау, Кам Лам, Да Бан, Суои Зау, расположенных в пределах провинции Кхань Хоа Центрального Вьетнама.

\section{Материал и методы исследований}

Сбор материала проводили с ноября 2010 по март 2011 года. В литорали рыб отлавливали бреднем длиной 5 м с размером ячеи 6 мм, в пелагиали - ставными сетями с ячеей 20-40 мм. Видовую принадлежность рыб определяли, используя ряд справочников, сводок и аннотированных списков [3-10]. Значимость отдельных видов рыб в сообществе оценивали по показателю абсолютной встречаемости (отношения количества проб, в которых обнаружен данный вид рыб, к общему количеству проб). Использовали стандартную в гидробиологии шкалу встречаемости: константные виды - встречаемость более $50 \%$, второстепенные - 25-50 \%, случайные - менее $25 \%$ [1; 2].

При отборе ихтиологического материала измеряли физико-химические характеристики водной среды - температуру, электропроводность, минерализацию, концентрацию кислорода, $p H$. Произведена батиметрическая съемка водоемов по сетке галсов с использованием эхолота Garmin, оборудованного навигационным модулем GPS.

(С) И. А. Столбунов, 2012 


\section{Результаты и их обсуждение}

Водохранилище Суои Чау $\left(12^{\circ} 30^{\prime}\right.$ с. ш., $109^{\circ} 02^{\prime}$ в. д.) расположено в северной части провинции Кхань Хоа и относится к бассейну реки Суои Ом За. Строительство водохранилища начато в 1977 и завершено в 1979 году. Площадь водохранилища составляет 0,6 км². Средняя глубина водоема - 1,5 м, наибольшая - 9 м. Водохранилище имеет обширную литоральную зону ( $10 \%$ общей площади водоема) с песчано-илистыми грунтами и хорошо развитой прибрежно-водной растительностью. За период наблюдений средняя температура поверхности воды в прибрежье составляла $24,5 \pm 1{ }^{\circ} \mathrm{C}$. Средняя минерализация воды $(p p m)-67 \pm 3$ мг/л, электропроводность $(\mu \mathrm{S})-134 \pm 6$ мкС/см (слабоминерализованное), $p H-7,6 \pm 0,3$. Водоем имеет оросительное и питьевое назначение. Оросительная система водохранилища позволяет устойчиво получать два урожая риса. Первый вегетационный цикл риса проходит с конца декабря по март, второй - с мая по август. В составе ихтиофауны водохранилища отмечено 32 вида, относящихся к 20 семействам (табл. 1). В прибрежье выявлено 20 видов, в открытой части - 27. Наиболее разнообразно семейство карповых рыб (Суprinidae) - 11 видов, остальные семейства представлены единичными видами.

Список видов рыб в литорали (л) и пелагиали (п)

Таблица водохранилищ Центрального Вьетнама (ноябрь 2010 - март 2011 г.)

\begin{tabular}{|c|c|c|c|c|}
\hline \multirow{2}{*}{ Семейство, вид } & \multicolumn{4}{|c|}{ Водохранилище } \\
\hline & Суои Чау & Кам Лам & Да Бан & Суои Зау \\
\hline 1 & 2 & 3 & 4 & 5 \\
\hline \multicolumn{5}{|l|}{ Anabantidae } \\
\hline Anabas testudineus (Bloch, 1792) & $\Pi$ & л, п & - & - \\
\hline \multicolumn{5}{|l|}{ Anguillidae } \\
\hline Anguilla marmorata Quoy \& Gaimard, 1824 & $\Pi$ & $\Pi$ & Л, П & $\Pi$ \\
\hline \multicolumn{5}{|l|}{ Belonidae } \\
\hline Xenentodon cancila (Hamilton, 1822) & л, п & л & л, п & л \\
\hline \multicolumn{5}{|l|}{ Chandidae } \\
\hline Parambassis siamensis (Fowler, 1937) & л, п & л & л, П & л, П \\
\hline \multicolumn{5}{|l|}{ Channidae } \\
\hline Channa gachua (Hamilton, 1822) & $\Pi$ & л, п & л, п & - \\
\hline Ch. striata (Bloch, 1793) & л, п & $\Pi$ & л, п & л \\
\hline \multicolumn{5}{|l|}{ Chichlidae } \\
\hline Oreochromis niloticus (Linnaeus, 1758) & л, п & л, п & л, П & л, п \\
\hline \multicolumn{5}{|l|}{ Claridae } \\
\hline Clarias batrachus (Linnaeus, 1758) & л, п & л, п & л, п & - \\
\hline C. macrocephalus Günter, 1864 & - & - & $\Pi$ & - \\
\hline \multicolumn{5}{|l|}{ Cobitidae } \\
\hline Lepidocephalichthys hasselti (Valenciennes, 1846) & $\Pi$ & $\Pi$ & - & - \\
\hline \multicolumn{5}{|l|}{ Cyprinidae } \\
\hline Cirrhinus molitorella (Valenciennes, 1844) & л, п & $\Pi$ & л, п & $\Pi$ \\
\hline Ctenopharyngodon idellus (Valenciennes, 1844) & - & - & л, п & $\Pi$ \\
\hline Cyprinus carpio Linnaeus, 1758 & - & - & л, п & $\Pi$ \\
\hline Esomus metallicus Ahl, 1923 & $\Pi$ & $\Pi$ & л, П & - \\
\hline Hemiculter krempfi Pellegrin \& Chevey, 1938 & - & $\Pi$ & - & - \\
\hline Henicorhynchus siamensis (Sauvage, 1881) & - & Л, п & - & - \\
\hline Hypophthalmichthys molitrix (Valenciennes, 1844) & л, п & - & л, п & - \\
\hline Mystacoleucus marginatus (Valenciennes, 1842) & л, п & л, п & л, п & л, п \\
\hline
\end{tabular}

Mystacoleucus marginatus (Valenciennes, 1842)

Окончание табл.

\begin{tabular}{|l|c|c|c|c|}
\hline \multicolumn{1}{|c|}{1} & 2 & 3 & 4 & 5 \\
\hline Osteochilus hasselti (Valenciennes, 1842) & л, п & л, п & л, п & л, $~$ \\
\hline O. lini Fowler, 1935 & л & л, п & - & - \\
\hline
\end{tabular}




\begin{tabular}{|c|c|c|c|c|}
\hline Poropuntius deauratus (Valenciennes, 1842) & л & - & - & - \\
\hline P. laoensis (Günter, 1868) & - & л, п & $\Pi$ & - \\
\hline Puntius brevis (Bleeker, 1850) & $\Pi$ & $\Pi$ & л, п & л, П \\
\hline P. jacobusboehlkei (Fowler, 1958) & л, П & - & л, п & л, п \\
\hline P. rhombeus Kottelat, 2000 & $\Pi$ & л, п & л, п & л, П \\
\hline Rasbora paviei Tirant, 1885 & л, П & л, п & л, п & л, П \\
\hline \multicolumn{5}{|l|}{\begin{tabular}{|l} 
Eleotridae \\
\end{tabular}} \\
\hline Oxyeleotris marmorata (Bleeker, 1852) & л & - & - & - \\
\hline \multicolumn{5}{|l|}{ Gerreidae } \\
\hline Gerres filamentosus Cuvier, 1829 & $\Pi$ & - & - & - \\
\hline \multicolumn{5}{|l|}{ Gobiidae } \\
\hline Glossogobius aureus (Akihito \& Meguro, 1975) & - & - & л & - \\
\hline G. giuris (Hamilton, 1822) & л & - & л & - \\
\hline Rhinogobius giurinus (Rutter, 1897) & - & - & л & - \\
\hline Rh. leavelli $($ Herre, 1935$)$ & л & - & л & - \\
\hline Stenogobius ophthalmoporus (Bleeker, 1853) & - & - & л & - \\
\hline \multicolumn{5}{|l|}{ Hemiramphidae } \\
\hline Dermogenys pusilla van Hasselt, 1823 & $\Pi$ & л, п & - & - \\
\hline Hyporhamphus limbatus (Valenciennes, 1846) & - & $\pi$ & - & - \\
\hline Zenarchopterus dunckeri Mohr, 1926 & $\Pi$ & л, п & - & - \\
\hline \multicolumn{5}{|l|}{ Notopteridae } \\
\hline Notopterus notopterus (Pallas, 1769) & л, п & л, п & л, п & $\Pi$ \\
\hline \multicolumn{5}{|l|}{ Ophichthidae } \\
\hline Caecula pterygera Vahl, 1794 & $\Pi$ & - & - & - \\
\hline \multicolumn{5}{|l|}{ Osphronemidae } \\
\hline Trichogaster trichopterus (Pallas, 1770) & л, п & л, п & л, п & $\Pi$ \\
\hline Trichopsis vittata (Cuvier, 1831) & Л, П & - & - & - \\
\hline \multicolumn{5}{|l|}{ Pristolepididae } \\
\hline Pristolepis fasciata (Bleeker, 1851) & $\Pi$ & - & $\Pi$ & - \\
\hline \multicolumn{5}{|l|}{$\begin{array}{ll} & \text { Siluridae }\end{array}$} \\
\hline Ompok bimaculatus (Bloch, 1794) & л, п & л, п & л, п & л, п \\
\hline \multicolumn{5}{|l|}{ Syngnathinae } \\
\hline Doryichthys martensii (Peters, 1868) & - & - & $\Pi$ & - \\
\hline Всего: & 32 & 26 & 30 & 17 \\
\hline
\end{tabular}

Примечание: прочерком обозначено отсутствие данного вида рыб в уловах.

Наиболее часто в уловах, проводимых в прибрежной зоне водохранилища, встречались Parambassis siamensis (100\%), Rasbora paviei (100\%) и Trichopsis vittata (100\%). По численности в прибрежье преобладали Parambassis siamensis, Cirrhinus molitorella, Osteochilus lini, Puntius jacobusboehlkei. В притоке водохранилища - p. Суои Ом За (Suoi Ong Gia), (12³0' с. ш., 10901' в. д.) - отловлены 2 экз. бычка Rhinogobius leavelli.

Водохранилище Кам Лам $\left(12^{\circ} 06^{\prime}\right.$ с. ш., $109^{\circ} 04^{\prime}$ в. д.) расположено в южной части провинции Кхань Хоа и относится к бассейну рек Суои Ба Ли, Суои Кок и Суои Чау. Строительство водохранилища завершено в 2000 году. Площадь его составляет 2,9 км². Средняя глубина водоема -4 м, наибольшая - 18 м. Средняя температура поверхности воды в прибрежье в период наблюдений составляла $24,8 \pm 0,4{ }^{\circ} \mathrm{C}$. Средняя минерализация воды $(p p m)-24,4 \pm 0,24$ мг/л, электропроводность $(\mu \mathrm{S})-48,8 \pm 0,63$ мкС/см (слабоминерализованное), $p H-7,8 \pm 0,07$. Водохранилище имеет оросительное и питьевое назначение. В составе проведенных уловов отмечено 26 видов, относящихся к 12 семействам рыб (табл.). В прибрежье водохранилища выявлено 20 видов рыб, в открытой части - 22 вида. Наиболее разнообразно также семейство карповых рыб (Cyprinidae) - 11 видов, семейство Hemiramphidae - 3 вида, семейство Channidae 2 вида. Остальные семейства представлены отдельными видами. В литоральной зоне водохранилища за период наблюдений наиболее часто встречаемыми видами являлись 
Oreochromis niloticus (88\%), Rasbora paviei (79 \%), Puntius brevis (63\%). В составе прибрежных группировок рыб доминирующими видами по численности являлись Rasbora paviei, Puntius brevis.

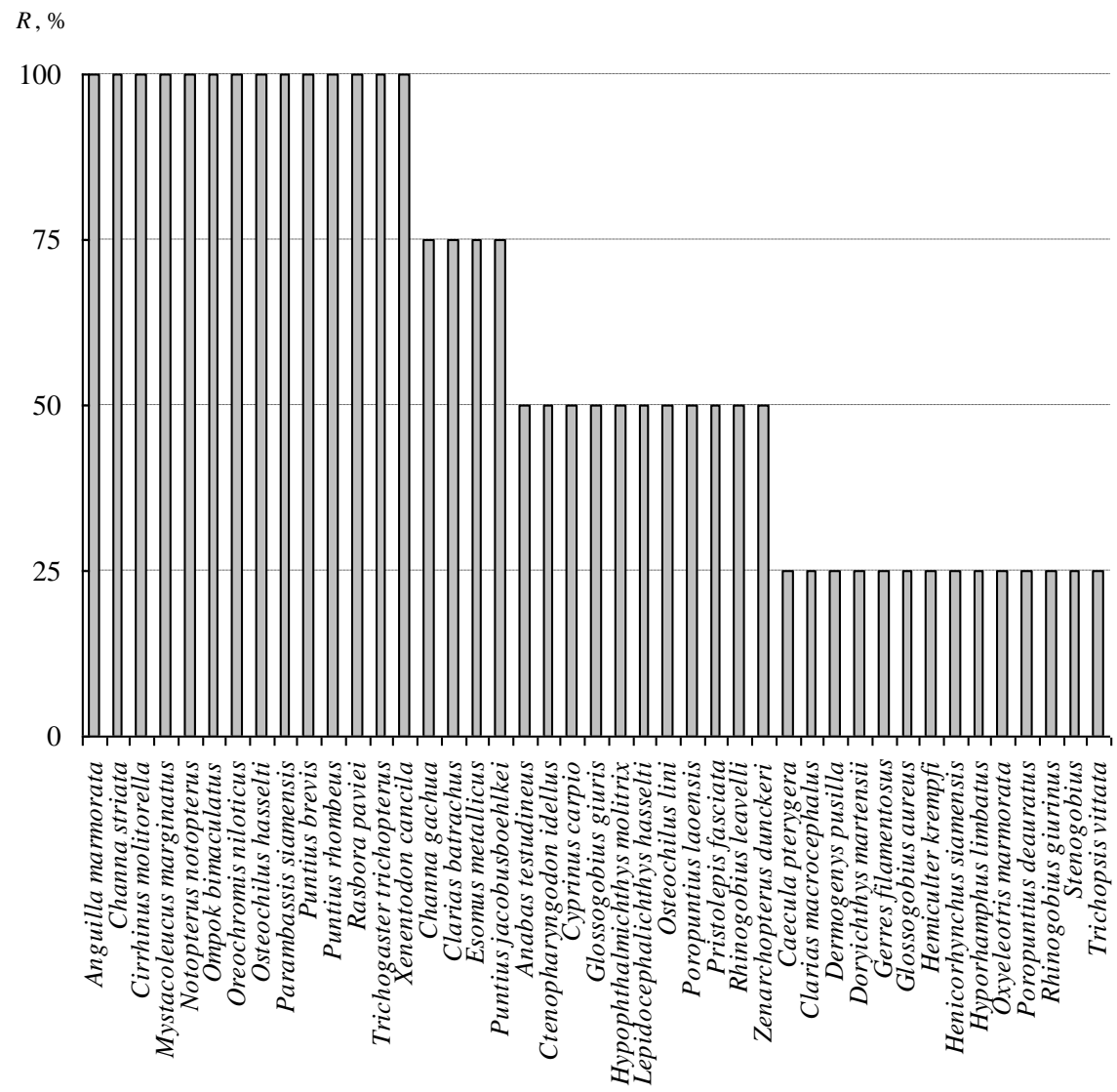

Рис. Абсолютная встречаемость $(R, \%)$ отдельных видов в составе ихтиоценозов исследованных водохранилищ

Водохранилище Да Бан (12³8' с. ш., $109^{\circ} 06^{\prime}$ в. д.) находится в северной части провинции Кхань Хоа и относится к бассейну рек Дабан, Че и Хом. Строительство водохранилища начато в 1978 и завершено в 1986 г. Площадь водохранилища составляет 6,7 км². Средняя глубина водоема - 11 м, наибольшая -24 м. В период наблюдений средняя температура поверхности воды в прибрежье составляла $24,2 \pm 0,5^{\circ} \mathrm{C}$. Средняя минерализация воды $(p p m)-11,4 \pm 0,24$ мг/л, электропроводность $(\mu \mathrm{S})-36,8 \pm 0,55$ мкС/см (слабоминерализованное), $p H-8,8 \pm 0,03$. Водохранилище имеет оросительное и питьевое назначение. На протяжении периода наблюдений в составе ихтиофауны водохранилища отмечено 30 видов, относящихся к 13 семействам рыб (см. табл.). В прибрежье отмечено 24 вида, в открытой части - 24. Наиболее разнообразны семейства карповых Cyprinidae (12 видов) и бычковых Gobiidae (5 видов) рыб. Остальные семейства представлены отдельными видами. По численности в прибрежных скоплениях рыб преобладали Rasbora paviei, Osteochilus hasselti и Puntius jacobusboehlkei.

Водохранилище Суои Зау $\left(12^{\circ} 10^{\prime}\right.$ с. ш., $109^{\circ} 03^{\prime}$ в. д.) находится в южной части провинции Кхань Хоа и относится к бассейну реки Зау. Площадь водохранилища со-

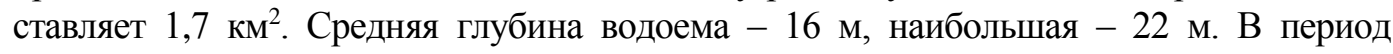
наблюдений средняя температура поверхности воды в прибрежье составляла 24,8 \pm $0,5^{\circ} \mathrm{C}$. Средняя минерализация воды $(p p m)-17,4 \pm 0,3$ мг/л, электропроводность $(\mu \mathrm{S})-$ 
$35,2 \pm 0,35$ мкС/см (слабоминерализованное), $p H-7,5 \pm 0,03$. Водохранилище имеет оросительное и питьевое назначение. Ихтиофауна водохранилища представлена 17 видами из 9 семейств рыб (см. табл.). В открытой части водоема в составе уловов отмечено 15 видов рыб, в прибрежной зоне - 11 видов. По численности в уловах преобладали Oreochromis niloticus, Parambassis siamensis, Xenentodon cancila. Абсолютная встречаемость отдельных видов в составе ихтиоценозов исследованных водохранилищ показана на рисунке. Встречаемость более $50 \%$ отмечена у 18 видов рыб (константные), у 25 видов - встречаемость составляла 25-50 \% (второстепенные).

В прибрежной зоне исследованных водоемов наибольшая плотность скоплений рыб отмечена в водохранилище Кам Лам $\left(5,5 \pm 0,5\right.$ экз./ $\left.\mathbf{M}^{2}\right)$. В литорали водохранилищ Суои Чау и Суои Зау численность рыб составила $4,3 \pm 0,8$ и $4,0 \pm 0,6$ экз./ $\mathrm{M}^{2}$, соответственно. Наименьшая численность рыб наблюдалась в прибрежье водохранилища Да Бан $-1,7 \pm 0,3$ экз./ $\mathrm{M}^{2}$.

\section{Заключение}

С ноября 2010 по март 2011 года получены предварительные данные о видовом составе и структуре ихтиофауны водохранилищ Центрального Вьетнама. Ихтиофауна исследованных водохранилищ представлена не менее чем 43 видами из 19 семейств. Наибольшее видовое разнообразие рыб отмечено в водохранилище Суои Чау (32 вида), наименьшее - в водохранилище Суои Зау (17). По значимости отдельных видов в составе ихтиоценозов исследованных водохранилищ 18 видов являются константными и 25 - второстепенными.

\section{Библиографические ссылки}

1. Иоганзен Б. Г. Основы экологии. - Томск : ТГУ, 1959. - 389 с.

2. Иоганзен Б. Г. Об определении показателей встречаемости, обилия, биомассы и их соотношения у некоторых гидробионтов / Б. Г. Иоганзен, Л. В. Файзова // Тр. ВГБО. - 1978. - Т. 22. C. $215-225$.

3. Fauna of Vietnam (Dong Vat Chi Viet Nam). - Vol. 2. - Hanoi, 2000. - 184 p.

4. Fauna of Vietnam (Ca Nuoc Ngot Viet Nam). - Vol. 1. (Cyprinidae). - Hanoi, 2001. - 623 p.

5. Fauna of Vietnam (Dong Vat Chi Viet Nam). - Vol. 10. - Hanoi, 2001. - 331 p.

6. Kottelat M. Fishes of Laos. - Sri Lanka : WHT Publications (PTE), 2001. - 198 p.

7. Rainboth W. J. Fishes of the Cambodian Mekong. - Rome : FAO, 1996. -265 p.

8. Serov D. V. Fishes of the River Cai / D. V. Serov, V. K. Nezdoliy, D. S. Pavlov. - Moscow : GEOS, 2003. $-164 \mathrm{p}$.

9. Serov D. V. The freshwater fishes of Central Vietnam / D. V. Serov, V. K. Nezdoliy, D. S. Pavlov. M. : KMK Scientific Press Ltd., 2006. - 364 p.

10. Vidthayanon Chavalit Field guide to fishes of Mekong delta. - Vientiane : Mekong River Commission, 2008. -288 p. 